\title{
Символ и символизация: сходство и различия интерпретаций в контексте различных психологических подходов
}

Символизация - процесс создания (науровне общественного сознания) и освоения (на уровне индивидуального сознания) понятий-символов, концентрирующих в обобщенной форме значимость их специфических свойств как «сверхважных» или «сверхреальных». Понятия-символы имеют функцию, отличную от любого иного понятия, поскольку выступают в роли универсальных индикаторов, ориентирующих познающего субъекта на значимости того контекста, который должен быть не просто индифирентно воспринят, а нуждается в осмыслении, оценке, определенной интерпретации. В рамках различных психологических подходов проблема символизации рассматривается и оченивается по-разному. Анализ различных трактовок данной научной категории позволяет выйти на интегративный уровень понимания механизмов развития символов и символизации.

Ключевые слова: символ, символизация, абстракция, эмпирическое и теоретическое обобщение, психосемантический образ, интерпретация, метафоризация, смыслообразование.

Символ является важной составляющей современного сознания, как на личностном, так и на групповом уровнях. Возникновение символов имеет длительную эволюционную историю в процессе культурного становления человечества. Этимологически понятие символа связано с греческим глаголом «соединять», «сталкивать», «сравнивать». Отражая общую логику формирования понятийной системы, функция символа вначале отождествлялась с предметно-образным компонентом психосемантической реальности, и в ее основе лежало эмпирическое обобщение. Предметы и отчужденные от них образы становились объектом поклонения (предметы поклонения, тотемы), возникали определенные действияритуалы, связанные со спецификой их использования. Однако по мере развития абстрактно-обобщающих значений (в результате перехода от эмпирического к теоретическому обобщению) и их фиксации на уровне устойчивых понятий на надличностном уровне в различных формах общественного сознания функция символа значительно расширилась. Возникли целые направления в познании окружающего мира, которые теперь уже не нуждались в образном наполнении, а возникали на уровне абстракции (отчуждения и обобщения) свойств от ранее созданного абстрактного значения. Так возникли математические науки, вся содержательная компонента которых есть всецело символическая система.

По мере развития гуманитарной составляющей в становлении общественных форм сознания и в этой области человеческого развития возникла необходимость в символизации. Символизация - процесс создания на абстрактно-обобщенном уровне понятий-символов, которые не просто являются знаком-аналогом, замещающим определенный предмет или явление, а концентрируют в обобщенной форме 
значимость их специфических свойств как «сверхважных» или «сверхреальных». Понятия-символы имеют функцию, отличную от любого иного понятия, поскольку они не просто являются носителями определенных значений, а выступают в роли индикатора, ориентирующего субъекта на значимости того контекста, который должен быть не просто воспринят, а нуждается в осмыслении и определнной интерпретации. Не следует смешивать символ и знак. Знак только обозначает известный предмет, его функция - служебная. Символ же обладает самоценностью, он есть органический элемент психической и духовной жизни. Можно предположить, что символ выступает в роле центрации по отношению к понятиям менее обобщенным, становится своеобразным эпицентром, который определенным образом влияет на понимание всего содержательного контента. Понятия-символы концентрируют в себе такие черты, как универсальность, глубину, уровень оценки события как компонента общественного сознания, отличающегося особой значимостью. Употребляя их в устном или письменном изложении своих мыслей, рассказчик апеллирует не к единичному событию или факту, а подчеркивает масштабность предмета осмысления. Если мы говорим: Отечественная война, диктатура, Холокост и т. д., то даже без обращения к конкретным историческим примерам выделяется оценочный компонент данного понятия. Это универсальный процесс, поскольку каждый представитель определенной культурной эпохи воспринимает значение данного понятия не только как совокупность определенным образом обобщенных свойств, но и как то, что уже содержит в себе маркировку на позитивное или негативное. Универсальные понятия-символы в силу специфичности той роли, которая возложена на них надличностными и личностными реалиями, привлекали внимание психологов в контексте разных подходов и интерпретаций.

Особый ракурс для исследования и освоения символа, определения его функций в психологическом знании раскрыл психоанализ (3. Фрейд), который в анализе индивидуального бессознательного вышел на проблему возникновения символа и мотивации символотворчества. Наличествующие первобытные влечения - особый вид сексуальной энергии (либидо), требующие немедленного разрешения и не получающие его, в силу этого вступающие в конфликт с реальными ситуациями и требованиями морали, способствуют появлению невротических симптомов, состоянию дискомфорта, напряжения и страхов. Блокируемые Эго, они вытесняются из этой сферы и воплощаются в сновидениях в виде символов, единичных, разрозненных или связанных между собой символических образов, в мифологических сюжетах, в сказках, в отрывочных галлюцинациях. «Ибо какую цель преследует творчество, как не избавить, символически, человека от томительных внутренних перенапряжений, перенести гнетущую его силу в другую, безопасную для его духа область!» [6, с. 45] Посредством символа становится возможным перенести акцентуализацию из одной области в другую, сгладить или исчерпать конфликт, облегчить внутреннее состояние человека. «Душа человечества выявляла себя от начала веков лишь в художественной фантастике, - иначе, что бы мы о ней знали! Ее творческая мощь постигается нами только в ее сновидениях, воплощенных 
в религии, мифы и произведения искусства. Никакая психология поэтому не в состоянии - это прочно внушил нашей эпохе Фрейд - доискаться до подлинно личного в человеке, если она рассматривает только его сознательные и ответственные действия; ей приходится спуститься вглубь, туда, где существо человека становится мифом и создает наиподлиннейшую картину его жизни, в творчески стремительном потоке стихийно-бессознательного» [6, с. 45].

«Из работ Фрейда следует, что невротические симптомы, сновидения, ошибочные действия и т. п. можно рассматривать как своеобразные знаки (тексты), замещающие вытесненные переживания (конфликт мотивов) и репрезентирующие их в сознании и поведении» [2, с. 83]. Из вышесказанного следует, что 3. Фрейд при образовании сновидений рассматривает два момента:

1) конкретные мысли, составляющие скрытое содержание (смысловое начало) и являющиеся внутренней речью, протекающей на уровне предсознания;

2) трансформацию этих мыслей в символы и символические образы явного содержания (процесс наглядной и символической репрезентации). Преобразование символических образов в сюжет есть их вторичная переработка (вторичный процесс).

Помимо смещения - одного из вариантов перевода скрытых мыслей в явное содержание, охватывающего репрезентацию значимых мыслей через второстепенные детали (операции по деконтекстуализации элементов скрытого содержания), 3. Фрейд характеризует и другой вариант - конденсацию - сочетание разных элементов (скрытых мыслей) и единого образа, где конденсированные образы сверхдетерминированы, имеют множество интерпритаций, считаются узловыми, т. к. к ним сходятся множественные мыслительные последовательности. Эти две операции - производные всех продуктов бессознательного. Такая кодировка скрытого содержания (конкретных мыслей) может быть представлена на самом разном знаковом материале: «знаки - символы и иконические знаки сновидений, знаки - индексы и иконические знаки ошибочных и симптоматических действий и т. д.» [2, с. 83].

Существовала и «вторая» теория символов, представленная моделью ребусов, согласно которой образы сновидений рассматривались как однозначные сексуальные символы, в соответствии образ - символ (знак), вне текста. Эту теорию 3. Фрейд заимствовал у В. Штекеля. При этом сверхдетерминированность редуцируется до однозначного механического детерминизма. Влияние этой теории распространилось у 3. Фрейда на гипертрофированное понимание сексуальности. Он разграничивал символы по половому признаку. Одни отождествляя с фаллосом, другую группу - с вульвой или с другой явно выраженной частью женского начала. И также считал такую технику вспомогательной, пользовался ею при изучении однотипных символов. «Фрейд пишет, что ошибки его предшественников сводятся к тому, что они пытались вывести смысл сновидений непосредственно из образов его явного содержания, а не из их связей (через поверхностные ассоциации) со 
скрытыми мыслями» [2, с. 84], что противоречит языку «символического». Далее следует, «что анализу (т. е. деконденсации и реконтекстуализации) подлежит не «пиктографический», а словесный текст, поскольку «пиктографический» текст имеет смысл как «означающее» словесное. А т. к. поверхностные ассоциации служат связующим звеном между скрытыми мыслями и явным содержанием, то их «знаковые соотношения», о которых говорит Фрейд, выявляются на основе данных ассоциативной техники» [2, с. 85].

Если 3. Фрейд видел в культуре систему запретов, ограничивающих естественные влечения и трактовал символ как орудие регламентации взаимодействия сознания и бессознательного, то его ученик К. Юнг наделил символы совсем иными функциями. Он понимал культуру не как систему давлеющих над человеком запретов, а именно как систему символов. Он считал человеческую потребность в символизации более настоятельной, чем какую-либо другую. С помощью символов человек создает модель окружающего мира, строит планы поведения и сценарии развития событий, ориентируется в историческом и социальном пространстве на универсальные схемы. Поскольку символы взаимно дополняют и проясняют друг друга, вся проблематика духовной жизни в интерпретации К. Юнга в значительной степени сводится к соотношениям символов, которые могут быть художественными, политическими, мифологическими. Символические образы являются, согласно Юнгу, соединительными звеньями между культурным наследием и опытом отдельной личности. Они служат матрицами познания. Помогая оформить и упорядочить впечатления, они создают перспективу развития личности, расставляя в «смысловые ниши» триумфы и несчастья, надежды и страхи, радости и горести [7].

Значительное содержательное приращение к интерпретации символа было создано Э. Фроммом - ученым, стремящимся выяснить механизм связи между психикой индивида и социальной структурой общества, где главной причиной тревоги и образования неврозов является конфликт, возникающий еще в детстве при столкновении малыша с враждебным ему миром, и который углубляется при недостатке любви и внимания.

В ряде работ Э. Фромм подчеркивает, что у человека есть неизменная сущность, сохраняющаяся как ядро во всех культурах и при всех исторических обстоятельствах, но это не биологически заданная природа, а всегда «вторая природа», собственно человеческий мир культуры. Но человеческое сознание окружено огромной областью бессознательного, которое не бездействует и не лежит спокойно в глубине, а неосознанно прорывается наружу и оказывает решающее воздействие на человеческое поведение, во многом обуславливая его. Поэтому не только в бессознательной сфере, но и на уровне сознания тяжелые жизненные ситуации достаточно часто рассматриваются людьми как нереальные, как иллюзии, как мифы. Людям легче посредством символизации переносить превратности судьбы, «уходя» в мир грез и мечты, отступая от трезвой мысли, т. к. человек испытывает дискомфорт и чувствует себя напряженно в разорванном, расколотом мире. Он интуитивно тянется кцелостности, к нерасчлененному мирочувствованию и смыслосозиданию, 
совершая процесс мифоконструирования-одного из важнейших факторов развития культуры. А миф освящает человеческое существование, придает существованию смысл и надежду. Он также помогает одолеть безжалостную, критическую направленность сознания и на всех уровнях способен снимать остроту мировоззренческих противоречий. Э. Фромм пишет о том, что сознание современного среднего человека является, главным образом, ложным сознанием, состоящим из вымыслов и иллюзий, а то, что человек даже и не осознает, является настоящей реальностью. И поскольку целью теории Э. Фромма является «здоровое» общество через возможности психоанализа «социальной и индивидуальной терапии», то Э. Фромм обращается к мифу, к сокровищнице мирового эмоционально-чувственного переживания, теоретического и проективного мышления, креативной деятельности, социального и коммуникативного опыта.

Миф предстает перед нами как выдающееся достояние этого опыта, как ценнейший материал жизни, как тип индивидуального человеческого самостроительства и уникальный способ существования. В мифе воплощаются тайные желания человека, его галлюцинаторные картины и драматургия бессознательного, творчески - преобразующее и нормативно - упорядочивающее начала. В понимании Э. Фромма, специфика мифа - это не строго аналитическое знание, но вместе с тем миф и не хаотичен. Он указывает на наличие в мифе своеобразной логики, позволяющей осваивать огромный материал бессознательного и иррационального, накопленный человечеством.

Занимаясь символами, Эрих Фромм дает им свою классификацию.

1. Условные (конвенциональные) символы - не имеющие никакой внутренней связи с обозначаемым и основаны на соглашении, «заключенном» между людьми, наиболее знакомые и используемые в повседневном языке (математические, технические символы, слова как способ выражения языка).

2. Случайные символы - возникающие по пространственно- временной смежности (принцип условного рефлекса И.П. Павлова), базирующиеся на случайном совпадении, имеющие индивидуальные характеристики и не являющиеся закономерностью (запах духов, способный вызывать определенный эмоциональный настрой и ассоциации с конкретным человеком).

3. Универсальные символы - основанные на внутренней связи между символом и символизируемым (исключающие случайностей, воспринимаемыми одинаково всеми людьми).

Последняя группа символов позволила внести мотивационную составляющую в трактовку механизма реализации символа на уровне индивидуального сознания, выделив интенсиональные и экстенсиональные значения символа для личности. К аналогичной трактовке придут и отечественные психологи, но значительно позже и в рамках иных методологических ориентиров.

Универсальные понятия-символы наиболее полно в рамках отечественной психологической школы представлены в культурно-исторической теории Л.С. Выготского. В контексте данной теории они рассматриваются как культурные 
символы. Сознание невозможно вне общества. По мнению Л.С. Выготского, психика не развивается сама по себе, человеческому развитию можно помочь специальными знаковыми системами психотехнических действий - работа с языком, мифами, символами, техниками взаимодействия (психологическими орудиями, медиаторами человеческого развития, ёмкими средствами фиксации общечеловеческого опыта). Уникальный человеческий путь онтогенеза состоит в усвоении общественно-исторического опыта в процессе обучения и воспитания - общественно выработанных способов передачи человеческого опыта и культурные понятия - символы как раз и являются одним из «орудий» освоения человеком социальной реальности. При этом переход от более простых (житейских) понятий к более абстрактным (глубинным) научным понятиям как раз и выявляет тот механизм, который характеризует специфику интересующего нас предмета исследования.

Введение Л.В. Выготским категории значения, смысла, символа и дальнейшее их субстантивирование в самостоятельные целостные научные дефиниции, насыщающие целый пласт психологического знания качественно новым уровнем интерпретации практически всего понятийного аппарата, имеет определенную, достаточно длинную предысторию (или, точнее сказать, параллельную историю, т. к. во временном аспекте зачастую эти исследования шли почти одновременно, однако ввиду дистанцированности отечественной психологии советского периода от европейской и американской психологии, ряд зарубежных работ выпал из процесса осмысления отечественными психологами). Поскольку именно интерио и экстерио соотношение в познании во многом определяют специфику и самобытность взаимоотношений между субъектом и миром, характеризуя значимость для познающего субъекта тех или иных объектов и явлений постигаемой им действительности.

Взгляды и трактовки Л.С. Выготского в интерпретации культурных понятийсимволов нашли своих продолжателей в двух авторитетных отечественных подходах:

-психосемантике;

-теории смысла и смыслообразования.

Психосемантический подход открывает путь к изучению личности через анализ ее индивидуального сознания. Основные положения психосемантики представлены в первую очередь работами психологов МГУ (Е.Ю. Артемьева, В.Ф. Петренко, А.Г. Шмелев, В.В. Столин, А.А. Нистратов, В.И. Похилько, О.В. Митина). Методологическую суть психосемантического подхода хорошо выразил А.Н. Леонтьев: «Сенсорные модальности ни в коем случае не кодируют реальность: они несут ее в себе» [1, с. 16].

Психосемантика берет начало от семантики. Семантика как часть семиотики «рассматривает знаки в их отношении к обозначаемым (не имеющим знаковой природы) объектам» [4, т. 3, с. 514]. «Наиболее важным предметом изучения для семиотики является язык, а потому она входит в качестве составной части в лингвистику (как 
семантика естественного языка) и в логику (как семантика формальных языков)» [там же]. Согласно Г. Фреге, природа языкового знака является тройственной. «Сам знак (единичный объект), во-первых, указывает на другой объект (значение знака), а во-вторых, на соответствующее означаемому объекту понятие (символ знака)» [4, т. 3, с. 514]. Согласно Ф. де Соссюру, знак является «единством означающего и означаемого» [там же]. В любом случае, язык естественный и формальный рассматриваются как средство для выражения неязыковых сущностей, т. е. для представления объективной реальности.

Психосемантика исследует те же вопросы, что и семантика, но в рамках индивидуального сознания человека, рассматривая преломление семантических структур в субъективной сфере личности. Три момента психосемантики имеют прямое или опосредованное отношение к проблеме символа и символизации в интересующем нас плане.

Во-первых, показано, что протекающие в сознании индивида процессы категоризации (в широком смысле включающие функционирование словесных понятий, образов, коммуникативных и ритуальных действий - символов) определяются субъективной значимостью воспринимаемого человеком «мира, других людей, самого себя» (В.Ф. Петренко). «Субъект что-либо классифицирует, оценивает, шкалирует, выносит суждения о сходстве и различии объектов». Значения, приобретающие в сознании человека смысловую для него ценность, являются, таким образом, стимуляторами классификаций. «Субъективно более значимые основания категоризации дают больший вклад в общую вариативность оценок объектов и соответствующие им факторы - координатные оси семантического пространства более сильно поляризуют анализируемые объекты. Пространство как «резиновое» растягивается по оси субъективно значимого фактора» [5].

Во-вторых, в психосемантике представлен достаточно убедительный вариант генезиса субъективного смысла, нашла отражение своеобразная интериоризация объективных значений, «сбрасывание» ими знаковой формы, переход в «живые» смыслы. Генетическая последовательность смыслообразования выглядит как «предсмыслы - образованные следы, зафиксированные в модальных свойствах (слой перцептивного мира), смыслы - следы внутри семантического слоя и личностные смыслы - составляющие образа мира, элементы ядерных структур субъективного опыта» $[1$, с. 30].

B-третьих, психосемантика привлекает теоретической и практической значимостью классификации образуемых смыслов. Создав «концептуальный остов психологии субъективной семантики» (Е.Ю. Артемьева), представители этого направления расклассифицировали смыслы, образующие семантический слой субъективного опыта, по основанию их вклада в целостный смысл предмета. «Частичным модальным смыслом мы называем след взаимодействия с объектом, представленный в заданной модальности. Целостный след, образующийся в семантическом слое после синтеза модальных смыслов, назовем полным смыслом» [там же]. 
Психосемантический подход к исследованию личности реализует парадигму «субъектного» подхода к пониманию другого через категоризацию символов. Содержательная интерпретация выделяемых структур (символов) требует увидеть мир «глазами познающего», почувствовать его способы осмысления мира. Реконструируемая в рамках субъективного семантического пространства индивидуальная система значений выступает своеобразной ориентировочной основой такого эмпатийного процесса, дает ему смысловые опоры на этапе принятия или преобразования смысла «символа» для себя из окраужающей семантической культуры.

Теория смысла и смыслообразования начинает отдифференцироваться от других направлений в психологии с монографии А.Н. Леонтьева «Деятельность. Сознание. Личность». Интегрируя исследования в различных областях психологического поиска, А.Н. Леонтьев дает определение значения, указывая на его наиболее существенные атрибуты: «Значение - это то обобщение действительности, которое кристаллизовано, фиксировано в чувственном носителе его, обычно в слове или словосочетании. Это идеальная, духовная форма кристаллизации общественного опыта, общественной практики. Круг представлений данного общества, его наука, сам язык его - все это суть системы значений. Значение принадлежит, прежде всего, миру объективно-исторических явлений. Но значения существуют и как факт индивидуального сознания. Человек познает мир не как Робинзон, делающий на необитаемом острове самостоятельные открытия. Человек в ходе своей жизни усваивает опыт предшествующих поколений людей, и это происходит именно в форме овладения им значениями и в меру этого овладения» [3, с. 186].

Показав, что значение - «это та форма, в которой отдельный человек овладевает общественным отраженным человеческим опытом» [там же], А.Н. Леонтьев подчеркивал, что «индивид не имеет собственного языка, выработанных им самим значений, осознавание им явлений действительности может происходить только посредством усвоения им извне «готовых» значений». Значения несут в себе фиксированные способы отражения, включая даже умения как обобщенный образ действия и в индивидуальном сознании «являются лишь более или менее полными и совершенными проекциями «надиндивидуальных» значений, существующих в данном обществе» [там же].

Значения в своем существовании как бы двойственны. «Они производятся обществом и имеют свою историю в развитии языка, в развитии форм общественного сознания, в них выражается движение человеческой науки и ее познавательных средств, а также идеологических представлений общества - религиозных, философских, политических. В этом объективном своем бытии они подчиняются общественно-историческим законам и вместе с тем внутренней логике своего развития. Другая их жизнь - их функционирование в процессах деятельности и сознания конкретных индивидуумов, хотя посредством этих процессов они только и могут существовать. В этой второй своей жизни значения индивидуализируются и «субъективизируются», но при этом они отнюдь не утрачивают своей общественно-исторической природы, своей объективности» [там же, с. 254]. 
Суть вопроса в том, что значения, «функционируя в сознании», являются в то же время независимыми от эмоциональной насыщенности переживаемого, от субъективной мотивации деятельности людей, от индивидуального отношения человека к деятельности.

Однако определение значений не дает возможности разобраться в способах и механизмах осознания. Для этого нужно обратиться к субъекту познания, рассматривая его как носителя активной субъективности, а не пассивного воспринимателя выработанных обществом значений. Само значение не определяет особенности сознания индивида. «Интроспективно значение отсутствует в момент сознания: преломляя воспринимаемое или мыслимое, само оно при этом не воспринимается и не мыслится. Это фундаментальный психологический факт. Поэтому хотя значение и может сознаваться, но лишь в том случае, если предметом сознания является не означаемое, а само значение, например, при изучении языка» [там же].

Определяя смысл через отношения, А.Н. Леонтьев вводит категорию «личностный смысл», выражающую не ситуативный выбор из семантического поля, а интегрированную целостность психического. «Личностные смыслы отражают мотивы, порождаемые действительными жизненными отношениями» и «выражают именно его (субъекта) отношения к сознаваемым объективным явлениям» [там же].

Личностный смысл является, по существу, отношением мотива к цели, имеет объективную предметную сторону и характеризует уникальную субъективность данного индивида. «Личностный смысл - это всегда смысл чего-то: «чистый», непредметный смысл есть такая же бессмысленность, как и непредметное существо» [там же, с. 244]. Именно через личностные смыслы значения как устойчивая система обобщений, стоящая за словом, одинаковая для всех людей, начинают принадлежать конкретному человеку и выражать его индивидуальность. «Функционируя в системе индивидуального сознания, значения реализуются не сами по себе, а через движение воплощающегося в них личностного смысла - этого для себя - бытия конкретного субъекта» [там же]. «Личностный смысл, следовательно, связывает значения с реальностью жизни субъекта в этом мире, с его мотивами. Личностный смысл и создает пристрастность человеческого сознания» [там же].

Конкретизируя вопрос о соотношении личностного смысла и смысла-символа (когда понятие несет в себе смысл, «раскристаллизация» которого порождает личностный смысл познающего), А.Н. Леонтьев отмечал, что между ними существует так называемая смысловая дистанция. Она может быть значительной, средней, короткой, в зависимости от степени совпадения личностного смысла воспринимающего субъекта и смысла-символа, который заключен в контексте воспринимаемого. Короткая смысловая дистанция возникает лишь при условии соответствия смысла контекстуального с предметным миром коммуникатора, сферой действительных мотивов его деятельности, его целостного бытия. Только при этом условии личностный смысл может стимулировать усвоение и осознавание смысла-символа, поможет субъекту постигнуть всю глубину авторского замысла при прочтении книги, просмотре спектакля, восприятии произведений искусства. 


\section{Литература}

1. Артемьева Е.Ю. Основы психологии субъективной семантики / под ред. И.Б. Ханиной. - М.: Наука; Смысл, 1999. - 350 с.

2. Гуманитарная коллекция. «Бессознательное». - Новочеркасск: Агентство «Сагуна», 1994.

3. Леонтьев А.Н. Деятельность. Сознание. Личность. - М., 1975.

4. Новая философская энциклопедия: в 4 т. / Ин - т философии РАН, Нац. Общ. научн. Фонд - М.: Мысль, 2000.

5. Петренко В.Ф. Психосемантика сознания: учебник. - М.: Изд-во МГУ, 1988. 208 c.

6. Цвейг С. «Зигмунд Фрейд». Из биографической трилогии «Врачевание и психика». - М.: Изд-во «Форкис», 1990.

7. Юнг К.Г. Введение в психоанализ. Гл. 5. - М., 1997. 